\title{
A comparative study between inj. ropivacaine $0.75 \%$ and inj.ropivacaine $0.75 \%$ with inj. dexmedetomidine in lumbar epidural anesthesia for vaginal hysterectomies
}

\author{
Shubhendu Bajpal ${ }^{1}$, Nanda Upadhyaya ${ }^{2, *}$, Rina Gadhavi ${ }^{3}$ \\ ${ }^{1}$ Senior Resident, Dept. of Critical Care, Lilawati Hospital, Mumbai, Maharashtra, ${ }^{2}$ Associate Professor, ${ }^{3}$ Professor \& HOD, \\ Dept. of Anaesthesia, CU Shah Medical College, Surendranagar, Gujarat, India
}

*Corresponding Author:

Email: upadhyaya.nb@ rediffmail.com

Received: $29^{\text {th }}$ July, 2016

Accepted: $11^{\text {th }}$ May, 2017

\begin{abstract}
Introduction: Regional anesthesia has lots of advantages compared to general anesthesia for Vaginal hysterectomy. Intrathecal anesthesia and Epidural anaesthesia are regional anaesthesia techniques used for Vaginal Hysterectomy.

Aim and Objectives: 1.To study the adjuvant effect of alpha 2 agonist DEXMEDETOMIDINE with local anesthetic (ROPIVACAINE $0.75 \%$ ) in lumbar epidural anesthesia in form of onset and lasting period of sensory and motor blockade, variation in hemodynamic parameter, post-operative analgesia.

Materials and Methods: The study population was randomly divided into, 25 patients in each group. 1 . Group $\mathrm{R}(\mathrm{n}=25)-20 \mathrm{ml}$ of $0.75 \%$ ropivacaine; 2 . Group $\mathrm{RD}(\mathrm{n}=25)-20 \mathrm{ml}$ of $0.75 \%$ ropivacaine $+1 \mu \mathrm{g} / \mathrm{kg}$ of dexmedetomidine. With the patients in sitting position, epidural space was identified by hanging drop method and confirmed by loss of resistance technique to air using 18G Tuohy needle via the midline approach at either L2-3 or L3-4 inter spinous space. An epidural catheter was fixed at $3 \mathrm{cms}$ inside the epidural space

Result and Interpretation: result shows the prolonged sensory and motor blockage in RD group. Onset of sensory and motor blockade is stastaticaly significant. Sedation score is higher in RD group. Difference in heamodynamic parameters were statistically not significant. Parameters and side effects between two groups.

Conclusion: Dexmedetomidine given epidurally with ropivacaine produces synergistic effect of profound and prolonged motor blockade and sensory blockade with better sedation and hemodynamic stability. Ropivacaine and dexmedetomidine can be a safe and effective alternate for epidural blockade in vaginal hysterectomies.
\end{abstract}

Keywords: Dexmedetomidine, Epidural anesthesia, Hemodynamic stability, Motor block, Ropivacaine, Sensory block.

\section{Introduction}

Regional anaesthesia is always safe and cost effective. It is the technique of choice for providing excellent post-operative analgesia. Regional anesthesia has lots of advantages compared to general anaesthesia for Vaginal hysterectomy.

Ropivacaine has all the benefits of bupivacaine such as less cardiac toxicity. ${ }^{1}$ It appears that it may be an ideal local anaesthetic for epidural anaesthesia. ${ }^{2-5}$ It has also been found that lipid solubility of ropivacaine is 2.9 times compared to that of 3.9 of bupivacaine. ${ }^{6}$ Hence ropivacaine was selected as the study drug in this study.

Among adjuvants opioids, ketaminutese, $\alpha 2$ agonists like clonidine, dexmedetomidine have all been studied as additives to local anaesthetics in different regional anaesthetic techniques each having its own pharmacological profile and side effects. All these agents provided prolonged duration of anesthesia analgesia, amnesia and excellent sedation and allayed anxiety to the patient with good hemodynamic stability when used in epidural route. The anaesthetic and the analgesic requirement get reduced to a huge extent by the use of dexmedetomidine because of its analgesic properties and augmentation of local anaesthetic effects as they cause hyperpolarisation of nerve tissues by altering trans membrane potential. Sedation, stable hemodynamic and an ability to provide smooth and prolonged post-operative analgesia are the main desirable qualities of an adjuvant in neuraxial anesthesia. $\alpha 2$ adrenergic agonists have both analgesic and sedative properties when used as an adjuvant in regional anesthesia.

Dexmedetomidine is a highly selective \& centrally acting $\alpha 2$ adrenergic agonist with an affinity eight times greater than that of clonidine. Various studies have shown that the dose of clonidine is $1.5-2$ times higher than dexmedetomidine and ion conductance at locus ceruleans in the brainstem. ${ }^{7}$ The stable hemodynamic parameters and the decreased oxygen demand due to enhanced sympathoadrenal stability makes it a very useful pharmacologic agent.

Hence this study was undertaken to compare $0.75 \%$ ropivacaine with dexmedetomidine and $0.75 \%$ ropivacaine alone in vaginal hysterectomies.

\section{Aims and Objectives}

1. To study the onset and duration of sensory and motor blockade in both the groups.

2. To elucidate the changes in hemodynamic parameters in both groups.

3. To assess the maximum dermatome level of 
sensory blockage in both groups.

4. To compare the sedation levels in both groups.

5. To compare the severity of adverse effects in both groups.

\section{Materials and Methods}

This is an observational study undertaken after obtaining permission from ethical committee. Fifty patients, posted for elective vaginal hysterectomies belonging to ASA class I and II were selected for the study. This study group was randomly divided into two with 25 patients in each group.

1. Group $\mathrm{R}(\mathrm{n}=25) 20 \mathrm{ml}$ of $0.75 \%$ ropivacaine

2. Group $\mathrm{RD}(\mathrm{n}=25) 20 \mathrm{ml}$ of $0.75 \%$ ropivacaine + $1 \mu \mathrm{g} / \mathrm{kg}$ of dexmedetomidine

\section{Inclusion criteria for the study:}

1. Adult female patients aged between 25 to 65 years

2. Patients of ASA class I and II

3. Weight between 50-70 kilograms

4. Height (150-180) cms

Exclusion criteria for the study:

1. Patients not willing for regional anaesthesia

2. Obese patient with BMI $>30$

3. Patients with psychiatric diseases

4. Contraindication of epidural anesthesia: a. Spine abnormality; b. Hematological disease- bleeding disorders; C. local site infection; d. Hemodynamically unstable patients.

5. ASA grade III and IV patients

6. Allergy to ropivacaine and dexmedetomidine

A routine pre-anaesthetic examination was conducted before surgery and details regarding clinical history and general physical examination were recorded. All routine investigations were carried out and informed written consent from all participants were obtained. All patients were kept fasting for six hours.

In the operating room after securing a peripheral intravenous line with $18 \mathrm{G}$ cannula and attachment of standard monitors (Non invasive blood pressure, spo2, Electrocardiography) baseline readings were recorded. I.V. preloading was done with $15 \mathrm{ml} / \mathrm{kg}$ of Ringer lactate solution over a period of 15- 20 minutes.

With the patients in sitting position and under strict aseptic technique, epidural space was identified by hanging drop method and confirmed by loss of resistance technique to air using $18 \mathrm{G}$ Tuohy needle via the midline approach at either L2-3 or L3-4 inter spinous space. An epidural catheter was fixed at $3 \mathrm{~cm}$ inside the epidural space. A test dose of $3 \mathrm{ml}$ of $2 \%$ lignocaine with 1:200000 adrenaline was injected through the catheter after aspiration. After checking out intrathecal and intravascular placement of the tip of the catheter, Inj. Ropivacaine $0.75 \%$ was injected in increments of $5 \mathrm{ml}$ and then the patients were made to lie in supine position.

Assessment of sensory and motor blockade was done at the end of each minutesute with the patient in supine position after injection of $20 \mathrm{ml}$ Inj. Ropivacaine $0.75 \%$ drug, which was taken at the starting for onset time for sensory and motor block, the maximum level of sensory block, duration of sensory and motor block and sedation score were recorded.

1. Sensory blockade was checked by using pin prick method. Onset of sensory blockade: It is taken as the time from the completion of the injection of the study drug till loss of sensation at T10 level. Duration of sensory block: It is taken from the time of injection till the patient complains of pain at the T10 dermatome.

2. Motor blockade was checked by using modified Bromage scale. Onset of motor blockade: It is taken from the completion of the injection of study drug till the patient achieved modified Bromage scale grade 1 motor blockade. Duration of motor block: It is taken from the time of injection till the patient gets complete motor recovery (Bromage 0 ). Bromage scale for motor blockage.

2.

\begin{tabular}{|l|l|}
\hline 1 & $\begin{array}{l}\text { Unable to perform the leg raise but can flex the leg on knee } \\
\text { articulation. }\end{array}$ \\
\hline 2 & Unable to flex the knee but can flex the ankle. \\
\hline 3 & Unable to flex the ankle but can move the toes. \\
\hline 4 & Unable to move the toes. \\
\hline
\end{tabular}

\section{Ramsays Sedation score for levels of sedation}

\begin{tabular}{|l|l|}
\hline Anxious, agitated, restless & 1 \\
\hline Cooperative, oriented and tranquil & 2 \\
\hline Responsive to commands only & 3 \\
\hline Brisk response to light glabellar tap or loud auditory & 4 \\
\hline
\end{tabular}




\begin{tabular}{|l|c|}
\hline stimulus. & \\
\hline $\begin{array}{l}\text { Sluggish response to light glabellar tap or loud auditory } \\
\text { stimulus }\end{array}$ & 5 \\
\hline No response to light glabellar tap or loud auditory stimulus. & 6 \\
\hline
\end{tabular}

2. Measurements of cardio respiratory parameters were recorded every 5 minutes for the first 10 minutes and then every 10 minutes till the end of surgery.

3. Comparison of postoperative block characteristics

i. Average time for regression to bromage 1

ii. Average time for sensory regression to S1dermatomes

4. Any side effects like Hypotension were noted and treated with increased rate of infusion of intravenous fluids and injection ephedrine $6 \mathrm{mg}$ (I.V) given in bolus doses.. Bradycardia $(<60$ beats/minutes) was treated with injection Atropine $0.6 \mathrm{mg}$ (I.V).

After the surgery, patients were shifted to the recovery room where they remained until there was complete recovery of sensory and motor blockade. Epidural top up was given with $10 \mathrm{ml}$ of $0.125 \%$ bupivacaine $+50 \mathrm{mg}$ tramadol once the patient complained of pain. Postoperatively vital parameters were recorded every 15 minutes. Any adverse events like nausea, vomiting, hypotension, bradycardia, respiratory depression and $\mathrm{O} 2$ desaturation, etc were noted.

\section{Results and Observations}

Statistical analysis were performed by descriptive and inferential statistics using the Student's unpaired $t$-test, using IBM SPSS (version 17.0; IBM, New York, USA) and GraphPad Prism (version 5.0; GraphPad Software Inc., California, USA). $P$-values less than 0.05 were considered statistically significant. Microsoft Word and Excel have been used to create tables, charts etc.

Table 1: Average Time for Onset \& Duration of Sensory Block

\begin{tabular}{|l|c|c|c|c|c|c|}
\hline & $\begin{array}{c}\text { Average time } \\
\text { (minutes) } \\
\text { for sensory } \\
\text { onset }\end{array}$ & SD & P Value & $\begin{array}{c}\text { Average } \\
\text { duration } \\
\text { (minutes) of } \\
\text { sensory block }\end{array}$ & SD & P Value \\
\hline Group R & 11.08 & 2.04 & \multirow{2}{*}{0.028} & 226.40 & 19.76 & $<0.0001$ \\
\hline Group RD & 9.92 & 1.55 & & 495.00 & 15.67 & \\
\hline
\end{tabular}

Average time for sensory onset in group $\mathrm{R}$ and group RD was 11.08 minutes and 9.92minutes respectively. The difference was highly significant between the groups $(\mathrm{p}=0.028)$.

Average duration of sensory block was $226.4 .0 \pm 19.76$ minutes in group $\mathrm{R}$ and $495.30 \pm 15.67$ minutes in group RD. There was statistically highly significant difference between the groups $(\mathrm{p}<0.0001)$.

Table 2: Average Time for Onset \& Duration of Motor Block

\begin{tabular}{|l|c|c|c|c|c|c|}
\hline & $\begin{array}{c}\text { Average time } \\
\text { (minutes) } \\
\text { for motor onset }\end{array}$ & SD & P Value & $\begin{array}{c}\text { Average duration } \\
\text { (minute) for } \\
\text { motor block }\end{array}$ & SD & $\begin{array}{c}\text { P } \\
\text { Value }\end{array}$ \\
\hline Group R & 32.88 & 6.95 & \multirow{2}{*}{$<0.0001$} & 184.0 & 17.79 & $\begin{array}{c}<0.000 \\
1\end{array}$ \\
\cline { 1 - 3 } & 19.00 & 3.28 & & 423.2 & 27.94 & \\
\hline
\end{tabular}

Average time of onset for motor block in group R and group RD was 32.88 minutes and 19.00 minutes respectively. There was statistically significant difference in both the groups. $(\mathrm{p}<0.0001$.)

Average duration of motor blockade was $184.00 \pm 17.79$ minutes in group $R$ and $423.20 \pm 27.94$ minutes in group RD. There was statistically highly significant difference between the groups. $(p<0.0001)$

Table 3: Maximum Level of Sensory Block Attained

\begin{tabular}{|l|c|c|c|}
\hline Max Sensory Level & Group R & Group RD & \multirow{2}{*}{ P Value } \\
\hline T4 & 04 & 18 & \multirow{2}{*}{0.0006} \\
\hline T6 & 17 & 07 & \\
\hline T8 & 03 & 00 & \\
\hline T10 & 01 & 00 & \\
\hline Total & 25 & 25 & \\
\hline
\end{tabular}


The maximum level of sensory block attained by group R and group RD was T4 in both groups. 18 patients of group RD attained T4 level whereas only 4 patients of group R attained the same level which was highly significant. (P 0.0006)

Table 4: Average Systolic BP, Diastolic BP \& Heart Rate in Both the Groups

\begin{tabular}{|c|c|c|c|c|c|c|}
\hline Duration & Group R & Group RD & Group R & Group RD & Group R & Group RD \\
\hline 0 & 134.08 & 121.92 & 88.32 & 79.32 & 93.04 & 90.28 \\
\hline 5 & 127.88 & 117.84 & 84.88 & 77.88 & 91.12 & 87.44 \\
\hline 10 & 123.6 & 116.44 & 82.32 & 76.92 & 89.92 & 81.44 \\
\hline 20 & 120.16 & 112.16 & 78.88 & 74.32 & 84.44 & 78.56 \\
\hline 30 & 117.72 & 112.64 & 77.52 & 74.84 & 82.6 & 79.08 \\
\hline 40 & 113.96 & 111.16 & 74.08 & 73.84 & 80.2 & 77.68 \\
\hline 50 & 112.72 & 109.72 & 73.16 & 71.8 & 78.64 & 74.04 \\
\hline 60 & 111.48 & 107.52 & 73.44 & 70.08 & 76.8 & 71.92 \\
\hline 90 & 113.72 & 108.75 & 73.92 & 70.54 & 76.76 & 70.33 \\
\hline 120 & 121.54 & 105.57 & 78.76 & 70.07 & 79.15 & 70.57 \\
\hline & \multicolumn{2}{|c|}{ P Value $=0.99$} & \multicolumn{2}{|c|}{$\mathrm{P}$ Value $=0.999$} & \multicolumn{2}{|c|}{$\mathrm{P}$ Value $=0.93$} \\
\hline
\end{tabular}

No statistically significant difference was found in the systolic BP in both the groups $(\mathrm{p}=0.99)$ at various intervals.

No statistically significant difference was seen in diastolic BP between both the groups $(\mathrm{p}=0.999)$ at various intervals.

No statistically significant difference was seen in average heart rates in both the groups at various intervals. $(\mathrm{p}=0.93)$

Table 5: Average Sedation Scores in Both Groups

\begin{tabular}{|l|c|c|}
\hline \multicolumn{1}{|c|}{ Duration } & Group R & Group RD \\
\hline 0 & 1.52 & 1.96 \\
\hline 5 & 1.84 & 2.12 \\
\hline 10 & 2.00 & 2.64 \\
\hline 20 & 2.24 & 3.28 \\
\hline 30 & 2.48 & 3.48 \\
\hline 40 & 2.48 & 3.72 \\
\hline 50 & 2.56 & 3.88 \\
\hline 60 & 2.56 & 4.12 \\
\hline 90 & 2.56 & 4.16 \\
\hline 120 & 2.54 & 4.07 \\
\hline
\end{tabular}

Average sedation score at 20 minutes in Group R and Group RD were 2.24 and 3.28 respectively. At 90 minutes the difference increased and average sedation score in Group R and Group RD were 2.56 and 4.16 respectively.

Table 6: Incidence of Complications in two groups

\begin{tabular}{|l|c|c|}
\hline \multicolumn{1}{|c|}{ Complications } & Group R & Group RD \\
\hline Nausea & - & - \\
\hline Vomiting & - & - \\
\hline Bradycardia & 1 & 3 \\
\hline Hypotension & 3 & 2 \\
\hline Desaturation & - & - \\
\hline Respiratory depression & - & - \\
\hline
\end{tabular}

\section{Discussion}

Ropivacaine produces lesser duration of sensory and motor blockade than Ropivacaine + dexmedetomidine, as dexmedetomidine causes significant prolongation of sensory and motor blockade ${ }^{8}$ and improves the quality of anaesthesia, sedation and perioperative analgesia. ${ }^{9}$
The potency of the local anaesthetics is correlated to the lipid solubility of the drug. The lower lipid solubility of Ropivacaine would predict that it is likely to produce a greater differential block for sensory and motor function than bupivacaine. ${ }^{10}$

Casati et al. ${ }^{1}$ in their study reported that patients receiving $0.5 \%$ Ropivacaine more frequently had an inadequate motor blockade during surgery than those 
receiving bupivacaine A pilot study conducted in ten patients using Ropivacaine $0.5 \%$ for epidural anaesthesia showed that many of the patients had inadequate sensory and motor blockade. Hence in this study $0.75 \%$ Ropivacaine was selected instead of $0.5 \%$ Ropivacaine. Dexmedetomidine dose used in this study was $1.0 \mathrm{mcg} / \mathrm{kg}$.

\section{Sensory Blockade}

1. Onset of sensory blockade: In this study the average time for onset of sensory analgesia at T10 was $11.08+/-2.04$ minutes in group R and $9.92+$ 1.55 minutes in group RD. This difference is statistically highly significant $(\mathrm{p}=0.028)$. The studies conducted by Bajwa SJ, Bajwa SK, Kaur J et $\mathrm{al}^{11}$ showed onset of sensory analgesia at $\mathrm{T} 10$ in ropivacaine + dexmedetomidine group was $8.52 \pm$ 2.36 minutes Vs $9.72 \pm 3.44$ minutes in ropivacaine + clonidine group and this is statistically significant similar to our study. Bajwa SJ, Arora V, Kaur J et $\mathrm{al}^{1}$ showed onset of sensory analgesia at T10 in ropivacaine + dexmedetomidine group as $7.12 \pm$ 2.44 minutes VS $9.14 \pm 2.94$ minutes inj. ropivacaine + fentanyl group which is also statistically significant similar to our study. These studies have added clonidine and fentanyl as adjuvants to ropivacaine proving that addition of adjuvant decreases the onset time of sensory block.

2. Maximum sensory level: In this study the maximum level of sensory block in group $\mathrm{RD}$ was $\mathrm{T} 4(\mathrm{n}=18)$ and in group R also it was T4 $(\mathrm{n}=4)$. The range of block was very wide in both the groups (T10-T4). Saravia P.S.F, Sabbag AT et $\mathrm{al}^{8}$ found maximum level of sensory block at T6 between control and dexmedetomidine groups. The studies conducted by Bajwa SJ, Bajwa SK and Kaur J et $\mathrm{al}^{11}$ showed maximum level of sensory block at T5-6 level in group RD compared to T6-T7 in group RC which is comparable to our study. Bajwa $\mathrm{SJ}$, Arora $\mathrm{V}$ and Kaur $\mathrm{J}$ et $\mathrm{al}^{1}$ showed maximum level of sensory block at T4-6 level in group RD compared to T5-T7 in group RF which is again comparable to this study.

3. Duration of sensory block: In our study the duration of sensory block is longer with Ropivacaine + Dexmedetomidine group compared with Ropivacaine group. It is $495+15.76$ minutes with ropivacaine + Dexmedetomidine group compared to $226.4+19.76$ minutes with ropivacaine group. This is statistically highly significant $(\mathrm{p}<0.0001)$.

Our study concurs with the study conducted by Bajwa SJ, Arora V and Kaur J et $\mathrm{al}^{4}$ who observed the average duration of analgesia to be $366.62 \pm 24.42$ minutes in group RD compared to $242.16 \pm 23.86$ minutes with in group RF which is highly significant.

\section{Motor Blockade}

1. Onset of motor blockade: The onset of motor blockade was $32.88+6.95$ minutes in group $\mathrm{R}$ and $19.00+3.28$ minutes in group $\mathrm{RD}$. This is statistically significant $(\mathrm{p}<0.0001)$.

2. Duration of motor block: The duration of motor block in groupRD was $423.2+27.94$ minutes compared to $184+17.79$ minutes in group $\mathrm{R}$. The duration of motor block with RD group is more prolonged than with group $\mathrm{R}$, which is statistically highly significant $(p<0.0001)$.

In a study conducted by Saravia P.S.F, Sabbag AT et $\mathrm{al}^{8}$ it was found that the duration of motor blockade was significantly higher in the dexmedetomidine group, averaging 30\% higher than that observed in the control group which was similar to the findings of our study.

\section{Hemodynamic Parameter}

1. Heart rate: Result of this study is consistent with the study conducted by Saravia P.S.F, Sabbag AT et $\mathrm{al}^{8}$ wherein there was no statistically significant difference in the heart rate intra and post-operatively.

2. Blood pressure: Studies conducted by Saravia P.S.F, Sabbag AT et al, ${ }^{8}$ no statistical significant difference was found in Systolic Blood Pressure, Diastolic Blood Pressure, Mean arterial Pressure in both the groups which compares with this study.

3. Sedation score:In this study, difference in average sedation score progressively increased from 10 minutes to 90 minutes which was statistically significant. This indicates the sedative effects of dexmedetomidine in epidural anaesthesia which can reduce the use of other cardio respiratory depressant sedatives. Results observed by Saravia P.S.F, Sabbag AT et $\mathrm{al}^{8}$ also found that the average sedation scores were significantly increasing in dexmedetomidine group compared to clonidine group $(\mathrm{p}<0.0001)$.

\section{Conclusion}

Dexmedetomidine given epidurally with ropivacaine produces synergistic effect of profound and prolonged motor blockade and sensory blockade with better sedation and hemodynamic stability. Ropivacaine and dexmedetomidine can be a safe and effective agent for epidural blockade in Vaginal hysterectomies.

This study reiterates the fact that the combination of Ropivacaine and dexmedetomidine given epidurally can be a good alternative in lumbar epidural anesthesia for vaginal hysterectomies.

\section{References}

1. Bajwa SJ, Arora V, Kaur J et al. Comparative evaluation of dexmedetomidine and fentanyl for epidural analgesia in lower limb orthopaedic surgeries. Saudi Journal of Anaesthesia 2011;Oct-Dec 5(4):365-70 
2. Casati A, Santorsola R, Aldegheri G, Ravasi F, Fanelli G, Berti M, et al. Intraoperative epidural anesthesia and postoperative analgesia with levobupivacaine for major orthopaedic surgery: a double-blind, randomized comparison of racemic bupivacaine and ropivacaine $\mathbf{J}$ Clin Anesth 2003;15:126-31.

3. Casati A, Putzu M. Bupivacaine, levobupivacaine and Ropivacaine: are they clinically different? Best Practice and Research Clinical Anaesthesiology 2005;19:247-68.

4. Katz JA, Bridenbaugh PO, Knarr DC, Helton SH, Denson DD. Pharmacodynamics and pharmacokinetics of epidural ropivacaine in humans. Anesth Analg 1990;70:16-21.

5. Concepcion M, Arthur GR, Steele SM, Bader AM, Cavino BG. A new local anesthetic, ropivacaine. Its epidural effects in humans. Anesthesia and Analgesia 1990;70:80-5.

6. Katz JA, Knarr DC, Bridenbaugh PO. A double blind comparison of $0.5 \%$ Bupivacaine and $0.75 \%$ Ropivacaine adminutesistered epidurally in humans. Regional anesthesia 1990;15:250-2.

7. Brown DL, Carpenter RL, Thompson GE. Comparison of $0.5 \%$ Ropivacaine and $0.5 \%$ Bupivacaine for epidural anesthesia in patients undergoing lower extremity surgery. Anesthesiology 1990;72:633-6.

8. Saravia P.S.F, Sabbag AT et al. Synergistic effect between dexmedetomidine and ropivacaine $0.75 \%$ in epidural anesthesia. Rev Assoc Med Bras 2008;Mar-April;54(2);110-5

9. Lopez SAO, Sanchez KAM et al. Epidural dexmedetomidine in regional anesthesia to reduce anxiety. Revista Mexicana de Anesthesiology 2008;Oct-Dec31(4):271-8.

10. Jaakola ML, Salonen M, Lentinen R, Scheinin H. The analgesic action of dexmedetomidine - a novel alpha-2 adrenoceptor agonist in healthy volunteer. Pain 1991;46:281-5.

11. Bajwa SJ, Bajwa SK, Kaur J et. Dexmedetomidine and clonidine in epidural anaesthesia:A comparative evaluation. Indian Journal of Anaesthesia 2011;Mar-Apr55(2):116.

12. Arthur GR, Feldman HS, Covino BG. Comparative pharmacokinetics of bupivacaine and Ropivacaine, a new amide local anesthetic. Anesth Analg 1988;67:1053-8.

13. Finucane BT, Sandler AN, McKenna J, Reid D, Milner AL, Friedlander $\mathrm{M}$ et al. A double blind comparison of Ropivacaine $0.5 \%, 0.75 \%, 1 \%$ and bupivacaine $0.5 \%$, injected epidurally, in patients undergoing abdominutesal hysterectomy. Can J Anaesth 1996;43:442-9.

14. Saraiva P.S.F, Sabbag A.T, Costa P.D.S, Brienz L.A., Dalto.H.B et al.Synergistic effect between dexmedetomidine and $0.75 \%$ ropivacaine in epidural anesthesia. Brazilian journal of medical 2008;54

15. Aanta R, Kanto J, Scheinin H, Kallio A. Dexmedetomidine $\mathrm{n}$ alpha-2 adrenoceptor agonist reduces anaesthetic requirements for patients undergoing minutesor gynecological surgeries. Anaesthesiology 1990;73:230-5.

16. Maarouf M. Evaluation of effect of dexmedetomidine in reducing shivering following epidural anaesthesia. ASA annual meeting Abstract AA-49.

17. Kanazi GE, Aonad MT, Jabbour Khonry SI, AJ-Jazzar MD, Alameddine MM, AL-Yaman R, et al. Effect of small dose dexmedetomidine or clonidine on the characteristics of bupivacaine - spinal block. Acta Anaesthesiol Scand 2005;50:222-7
18. Vieira AM, Schnaider TB et al. Epidural clonidine or dexmedetomidine for post-cholecystectomy analgesia and sedation. Rev Bras Anestesiol 2004;Aug;54(4):473-8

19. Schnaider TB, Vieira AM et al. Intraoperative analgesic effect of epidural ketaminutese, clonidine or dexmedetomidine for upper abdominutesal surgery. Rev Bras Anestesiol 2005;Oct55(5):525-31

20. Wahlander S, Frumento RJ et al. A prospective, double-blind, randomized, placebo controlled study of dexmedetomidine as an adjuvant to epidural analgesia after thoracic surgery. J Cardiothorac Vasc Anesth 2005;Oct; 19(5):630-5.

21. Coskuner I, Tekin $\mathrm{M}$ et al. Efect of dexmedetomidine on the duration of anaesthesia and wakefulness in bupivacaine epidural block. European Society of Anesthesiology 2007; June 24(6):535-40. 